\title{
Institutionalisation and schizophrenia in Japan: social environments and negative symptoms
}

\author{
Nationwide survey of in-patients \\ IWAO OSHIMA, YOSHIO MINO and YOSHIMASA INOMATA
}

\begin{abstract}
Background The number of psychiatric beds per capita in Japan is the highest in the world, and a replication of earlier British research is needed to identify possible means of improving the mental health system.
\end{abstract}

\begin{abstract}
Aims To describe the current situation of psychiatric hospitals in Japan and to examine the relationship between negative symptoms of schizophrenia and social environments.
\end{abstract}

\begin{abstract}
Method In-patients with schizophrenia were randomly selected from 139 hospitals. Data were obtained for 2758 participants using several scales, including the Manchester Scale and social environment scales.
\end{abstract}

\begin{abstract}
Results Negative symptom scales showed a significant correlation with understimulating social environments in hospitals.
\end{abstract}

\section{Conclusions This study confirms the results from the UK and provides evidence for the importance of community-based care and for providing more-stimulating rehabilitation environments.}

\section{Declaration of interest None.} Funding detailed in Acknowledgements.
The study by Wing \& Brown (1970) showing the effect of understimulating social environments in psychiatric hospitals on negative symptoms of schizophrenia has influenced psychiatric hospital reform and promoted efforts towards community mental health in the UK. To date, only one replication study, by Curson et al (1992), has been conducted in the UK, where deinstitutionalisation is now advanced. As this research is only possible when a country has not yet fully engaged in the process of deinstitutionalisation, a nationwide cross-sectional survey was conducted in Japan to examine the relationship between negative symptoms of schizophrenia and social environments to identify possible means of improving the mental health system. In addition, the current situation regarding psychiatric hospitals in Japan is described.

\section{Mental health care in Japan}

Although many Western countries over the past two or three decades have been trying to establish more-appropriate community mental health policies for people with severe mental illness and have gradually decreased the number of psychiatric beds (Leff, 1993; Salokangas \& Saarinen, 1998; Lamb \& Weinberger, 2001), few attempts at deinstitutionalisation have been made in Japan. In fact, the number of psychiatric beds had been on the rise until recent years (Mino et al, 1990; Oshima et al, 2002). The number of psychiatric beds per 100000 persons in 1998 was 284, which was the highest ratio in the world (Fig. 1). In addition, conditions within psychiatric hospitals in Japan are severe, as we describe below. Nevertheless, serious discussion about possible plans to establish community care programmes as a substitute for psychiatric in-patient care has just begun.

The characteristics of the psychiatric inpatient population and psychiatric hospitals listed here are derived from data provided by Japan's Ministry of Health and Welfare (1999) and the Zenkaren Health and Welfare Research Institute (2000). In Japan, $71 \%$ of psychiatric inpatients remain in hospital for 1 year or longer and the average length of stay is 8.5 years. In addition, there has been a gradual ageing of in-patients, with $29.5 \%$ of patients being over the age of 65 years and $64.6 \%$ over the age of 50 years. The percentage of involuntary admission cases is no less than $32 \%$, whereas that of unlocked wards is only $40 \%$. The in-patient wards are very restrictive environments. Specifically, in a nationwide survey, we found that the quality of life within psychiatric hospitals is much poorer than that in sheltered accommodation under the Livelihood Protection Law, which was enacted to ensure a minimum level of quality of life in Japan (Zenkaren Health and Welfare Research Institute, 1994; Oshima et al, 1996).

On the other hand, progress has been made since the mid-1980s in community mental health policy. Social rehabilitation facilities in line with the new mental health law, amended in 1987, have been established in several districts across Japan. Recently, various types of community mental health programmes have been put in place, although the provisions allocated for these programmes are as yet insufficient.

Nevertheless, such community care programmes have not been effective in solving the problems of long-stay patients in Japan. According to several nationwide surveys, $30-60 \%$ of patients resident in psychiatric hospitals have been evaluated by psychiatrists as being capable of living within the community, if community support programmes were available (Zenkaren Health and Welfare Research Institute, 1998). Furthermore, approximately $60 \%$ of long-stay patients in several nationwide surveys expressed a wish to be discharged from the psychiatric hospital in which they were staying (Zenkaren Health and Welfare Research Institute, 1998).

\section{METHOD}

\section{Participants}

Psychiatric hospitals from across Japan, whose administrators understood the aim and importance of this research, took part in the survey. In order to introduce the study, a prospectus and a sample of research kits were sent to 534 hospitals 


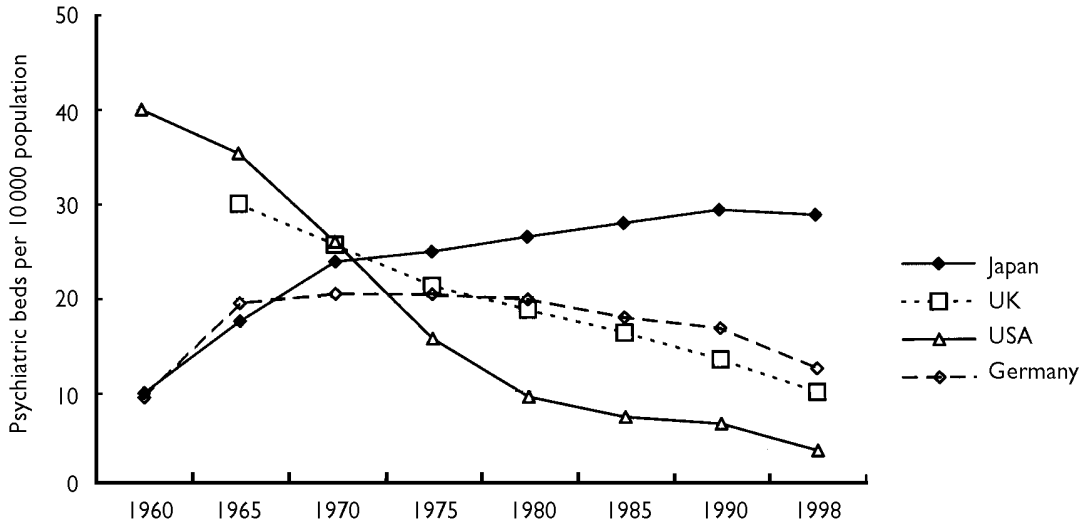

Fig. I Psychiatric beds per 10000 population since 1960: rates for four countries. Year 2000 data from the Organisation for Economic Cooperation and Development (see http://www.oecd.org) (data for Germany prior to 1990 are for West Germany only).

(32.1\% of psychiatric hospitals in Japan), including public hospitals, private hospitals in a certain mutual aid organisation, and hospitals that had family self-support organisations within them. Favourable replies were received from 139 hospitals $(26 \%)$. The total number of psychiatric beds within these hospitals was 42063 , representing $12 \%$ of psychiatric beds in Japan.

To recruit participants into the study, each hospital made a list of all patients meeting the following criteria: a diagnosis of schizophrenia according to DSM-III-R (American Psychiatric Association, 1987) and a duration of hospital stay of at least 1 year on the day of data collection. Each hospital then sent its list to the investigator, who randomly selected 20 people from each list using patient identification numbers. For six hospitals in which the total number of cases did not reach 20, all cases that satisfied the criteria were selected. Out of the 139 hospitals that participated in this study, we randomly selected 30 patients from 20 hospitals that agreed to participate in more intensive research, the results of which are analysed elsewhere (further details available from the author upon request).

The study by Wing \& Brown (1970) considered only women under the age of 60 years; however, we included male and female in-patients of all ages. Moreover, our definition of 'long-stay' was a duration of hospitalisation of 1 year or longer, compared with a criterion of 2 or more years in the original study. Inclusion criteria were also different because the data were collected to answer several distinct research questions in this nationwide survey, such as assessing the needs for community support resources. However, we conducted an additional analysis using the same criteria as Wing \& Brown (1970) to compare results $(n=714)$.

A total of 2898 patients fulfilled the inclusion criteria, and 2758 patients $(95.2 \%)$ agreed to participate. Sample characteristics are as follows: $57.8 \%$ of participants were male, and the average age and mean length of stay of all participants were 51.9 years and 13.5 years, respectively. These features are consistent with national statistics in Japan (Ministry of Health and Welfare, 1999). With regard to the features of the participating hospitals, the proportion of public hospitals $(39.6 \%)$, the mean number of psychiatric beds (309 beds) and the proportion of unlocked wards $(46.4 \%)$ were all higher than national averages. Other features of the hospitals, such as characteristics of inpatients and proportion of medical staff, are consistent with national data.

\section{Procedure and measures}

Two sets of measures were taken. Hospital psychiatrists assessed psychiatric symptom scales, and nurses caring for the participants provided information on social environments and clinical conditions other than psychiatric symptoms. All data except hospital data were collected for each participant.

Research kits, including the rating scales, questionnaires and research manuals, were sent to the hospitals taking part. Research was conducted according to the manuals at each hospital. Rating scale scores and completed questionnaires were collected by each hospital and returned to the investigator. The survey was conducted during January and February 1995.

Most of the scales and variables used were identical to those used by Wing $\&$ Brown (1970). Some were modified to take into account differences between Japanese and British psychiatric hospitals and some specific characteristics of this study. Standardised symptom scales such as the Manchester Scale (see below) were also included.

\section{Clinical condition}

Manchester Scale. The Manchester Scale is a five-point symptom rating scale developed by Krawiecka et al (1977). For this study, we used a Japanese version of the scale (Takekawa et al, 1994): symptoms of chronic mental illness are evaluated with eight items, sensitive to therapeutic changes and with easily administered sub-scales. A simplified interview schedule was prepared. Among the eight items, four ('flattened, incongruous affect', 'poverty of speech, mute', 'incoherence and irrelevance of speech', 'coherently expressed delusions') were the same as items on the Symptom Rating Scale (SRS) used by Wing \& Brown (1970) to evaluate the primary disabilities of schizophrenia. This allowed us to classify patients according to Wing's hierarchical clinical classification based on the SRS (Wing, 1961; Krawiecka et al, 1977). Although each item of the Manchester Scale is usually scored as $0-4$, we converted this to a range of $1-5$, which is the same scoring as the SRS. The following subgroups were defined by the same clinical classification as used by Wing (1961), based on the SRS:

(a) moderately impaired

(b) coherent delusions predominant

(c) incoherence of speech predominant

(d) poverty of speech predominant

(e) mute or almost mute.

Psychiatrists in charge of the participating patients evaluated this scale.

Ward Behaviour Rating Scale. The Ward Behaviour Rating Scale (WBRS) is a 12item, three-point rating scale, developed by Wing (1961) to evaluate the primary disabilities of schizophrenia based on 
nurses' daily observation of ward behaviours. It consists of two sub-scales: the Social Withdrawal Score (WBRS-SWS), which has eight items scored from 0 to 16, and the Socially Embarrassing Behaviour Score (WBRS-SES), consisting of four items scored from 0 to 8 . Cronbach's coefficient for each scale was 0.77 and 0.61 , respectively. Nurses in charge of the patients evaluated this scale.

Negative attitude to discharge. A single-item scale was developed by Wing \& Brown (1970) to evaluate the secondary disabilities of schizophrenia. Psychiatrists interviewed and evaluated the participants using a simplified interview schedule. Anchor points of this scale are: 1 , strongly desires to leave hospital; 2, desires to leave hospital in some way; 3 , ambivalent or vague; 4 , indifferent; 5, wishes to stay. Psychiatrists responsible for the patients evaluated this scale.

\section{Social environment}

The social environment scales were evaluated by nurses caring for the patients.

Personal Possessions Scale. This scale measured the number of personal possessions out of 21 possible items that patients could possess on psychiatric wards in Japan, and that are necessary for daily life. The items were selected from the personal possessions list of Wing \& Brown (1970), and modified to take into consideration the situation and culture in psychiatric hospitals in Japan. Cronbach's coefficient was 0.83 .

Nurses' Opinions about Patients Scale. Nurses evaluated a nine-item scale about patients' ability to cope with certain everyday activities and responsibilities. Items were selected from the scale developed by Wing $\&$ Brown (1970), and were likewise modified to take into account the situation and culture in Japanese psychiatric hospitals. Cronbach's coefficient was 0.83 .

Patient's Occupation Scale. This is a singleitem scale about recent occupation, contact with the outside world and physical treatment, developed by Wing \& Brown (1970). This scale was completed using the questionnaire filled out by nurses about the patient's ward behaviour.

Contact with the Outside World Scale. This is a single-item scale developed by Wing $\&$
Brown (1970), and was completed using the questionnaire about the patient's ward behaviour.

Ward Restrictiveness Scale. This is a 30 -item scale, completed by the nurse responsible for each participant, about restrictions on patients' movements and their daily life, limiting autonomy and self-determination. Items were selected from the scale developed by Wing \& Brown (1970), and also culturally modified. Among them, seven items about objective indices of the ward's structure and function were analysed separately. Other items were rated as 'agree', 'disagree' or 'could not decide' by the nurse. One point was given to each item if it was considered restrictive ('agree' or 'disagree', depending on the item). These represented items that could be assessed objectively by the nurses, and were intended to be independent of the symptoms and social functions of the patients. Cronbach's coefficient was 0.86 .

\section{Analysis}

Wing \& Brown (1970) described the adverse effects of prolonged hospital stay on people with schizophrenia in terms of primary disabilities ('clinical poverty' syndromes and florid symptoms) and secondary disabilities (a negative attitude to discharge). By means of cross-sectional and longitudinal studies, they found that a relationship exists between these disabilities and understimulating social environments as well as length of stay. We aimed to replicate the results of Wing \& Brown in terms of the influence of social environments and length of stay on 'clinical poverty' syndromes and negative attitude to discharge through a cross-sectional design.

Wing \& Brown (1970) measured 'clinical poverty' syndromes in terms of 'flatness of affect' and 'poverty of speech' using the SRS and the WBRS-SWS. They assessed florid symptoms by 'incoherence of speech' and 'coherently expressed delusions' using the SRS and WBRS-SES. We also adopted the WBRS-SWS and WBRS-SES, and four equivalent scales in the Manchester Scale. We defined 'clinical poverty' syndromes as negative symptoms, and florid symptoms as positive symptoms.

First, we compared the proportions of primary and secondary disabilities of longstay patients in Japan with those in the UK in the 1960s and 1990s (Table 1). We then analysed the influence of social environments and length of stay on these disabilities using correlations and multiple regression analysis with negative symptom scales and negative attitude to discharge as dependent variables (see Table 3). In addition, we used the five social environment scales, and four of these scales (excluding the Nurses' Opinions about Patients Scale), as independent variables, and examined multiple correlation coefficients. The reason for excluding the Nurses' Opinions about Patients Scale from the analysis was that it was considered to be the most subjective of the five social environment scales, and was also much influenced by poor clinical condition of the participant. We have to consider the possibility that we overestimated the effects of those scales. For the same reason we examined differences between the Ward Restrictiveness Scale and the other four scales, because it was considered to be the most objective and the least influenced by the participants' clinical condition.

All statistical analyses were carried out using the Statistical Package for the Social Sciences, version 9.

\section{RESULTS}

\section{Clinical condition of patients}

Table 1 shows clinical and social data concerning this Japanese sample compared with two British studies (Wing \& Brown, 1970; Curson et al, 1992). The proportion of those assessed as moderately impaired using Wing's clinical classification was $40.1 \%$. Among those who were severely impaired, the proportion with 'coherent delusions' was the highest. The combined proportion of 'poverty of speech' and 'mute or almost mute', which was $41 \%$ in the study by Wing \& Brown (1970), was only $9.5 \%$ in our study. The percentage of those wishing to stay in hospital was lower $(16.8 \%)$ than in the British studies. The means of WBRS-SWS and WBRS-SES were comparable to a median value in the British studies.

\section{Social environments}

Among social environment variables, the current research results that can be compared with British studies are shown in the lower part of Table 1 . The mean score on the occupation scale was 3.7 , which was lower than the means for all of the British hospitals, except for Severalls Hospital. On the other hand, the mean score 


\begin{tabular}{|c|c|c|c|c|c|}
\hline & \multirow{2}{*}{$\begin{array}{l}\text { This study } \\
(n=2758)\end{array}$} & \multicolumn{3}{|c|}{ Wing \& Brown (1970) } & \multirow{2}{*}{$\begin{array}{c}\text { Curson et al (1992) } \\
\text { Horton } \\
\text { Hospital }\end{array}$} \\
\hline & & $\begin{array}{c}\text { Netherne } \\
\text { Hospital }\end{array}$ & $\begin{array}{c}\text { Mapperley } \\
\text { Hospital }\end{array}$ & $\begin{array}{l}\text { Severalls } \\
\text { Hospital }\end{array}$ & \\
\hline \multicolumn{6}{|l|}{ Clinical scales } \\
\hline \multicolumn{6}{|l|}{ Wing's clinical classification } \\
\hline \multicolumn{6}{|l|}{ Moderately impaired (\%) } \\
\hline No florid symptoms, poverty of speech or flatness of affect & $10.5 \quad(n=289)$ & 10 & 15 & 8 & 3 \\
\hline Moderate symptoms only & $23.4 \quad(n=644)$ & 21 & 19 & 13 & 22 \\
\hline Moderate speech symptoms but severe flatness of affect & $6.3(n=173)$ & 9 & 5 & 2 & 34 \\
\hline Total of moderately impaired & $40.1 \quad(n=1106)$ & 40 & 39 & 23 & 59 \\
\hline \multicolumn{6}{|l|}{ Severely impaired (\%) } \\
\hline Coherent delusions predominant & $34.8(n=960)$ & 17 & 8 & 6 & 14 \\
\hline Incoherence of speech predominant & $14.1 \quad(n=388)$ & 17 & 14 & 15 & 12 \\
\hline Poverty of speech predominant & $2.8(n=77)$ & 20 & 25 & 32 & 9 \\
\hline Mute or almost mute & $6.7(n=186)$ & 6 & 14 & 24 & 6 \\
\hline \multicolumn{6}{|l|}{ WBRS sub-scale scores (mean) } \\
\hline Social Withdrawal (1-16) & 4.3 (s.d. $=3.3)$ & 2.9 & 4.6 & 5.4 & 3.6 \\
\hline Socially Embarrassing Behaviour (I-8) & I.8 (s.d.= I.8) & 1.2 & 2.3 & 1.3 & 1.5 \\
\hline \multicolumn{6}{|l|}{ Attitude to discharge (\%) } \\
\hline Wishes to leave & $34.3(n=946)$ & & 19.0 & & \\
\hline Ambivalent or vague & $28.7(n=791)$ & & 19.0 & & \\
\hline Indifferent & $18.2(n=501)$ & & 10.3 & & \\
\hline Wishes to stay in hospital & $16.8(n=464)$ & & 28.5 & & 38.0 \\
\hline \multicolumn{6}{|l|}{ Social scales' } \\
\hline Patient's occupation (0-15): mean & 3.7 (s.d.=3.4) & 6.0 & 5.5 & 2.6 & 4.3 \\
\hline Contact with outside world (3-15): mean & 6.3 (s.d.=3.7) & 6.9 & 6.4 & 2.9 & 6.4 \\
\hline \multicolumn{6}{|l|}{ Nurses' opinions about patients (\%) } \\
\hline Allowed to have matches or lighters & 65.8 & 79 & 27 & 21 & \\
\hline Appreciates money & 59.6 & 84 & 60 & 33 & \\
\hline Allowed out with a patient of opposite gender & 44.0 & 72 & 25 & 20 & \\
\hline Could work outside but live in hospital & 23.5 & 17 & II & 7 & \\
\hline
\end{tabular}

WBRS, Ward Behaviour Rating Scale.

I. Other scales shown in Table 2.

of contact with the outside world was 6.3 , which was almost the same as in the British studies. The proportions of those allowed to have matches or lighters and to work outside were evaluated more favourably than those of British studies.

Table 2 shows the distribution of scores on the social environment scales and variables that were not presented in the British studies. The most notable item of the Ward Restrictiveness Scale was that the proportion of high room occupancy (seven or more patients per ward) was $23 \%$. The proportion of those with three or more prohibited possessions was also over $20 \%$.

The mean score of the Nurses' Opinions about Patients Scale, shown in the lower part of Table 2, was 6.1, out of a maximum score of 9 . The mean score on the Personal Possessions Scale was 8.9, out of a maximum of 21 , and that on the Ward Restrictiveness Scale was 14.5, out of a maximum of 35 .

\section{Relationship of length of stay to clinical condition}

Correlations between clinical condition scales, negative attitude to discharge and length of stay are shown in the upper part of Table 3. There were significant positive correlations between each negative symptom scale and between negative attitude to discharge and length of stay.

Conducting the same analysis using Wing \& Brown's (1970) criteria demonstrated that the length of stay had a significant low association with all negative symptom scales $(r=0.14-0.16)$ and negative attitude to discharge $(r=0.25)$.

\section{Relationship of social environment to clinical condition}

The relationships between the clinical condition scales and the social environment scales are shown in Table 3. A moderate correlation was found for each negative symptom scale $(r=0.41-0.63)$. On the other hand, a somewhat weaker correlation was demonstrated for the three scales of positive symptoms $(r=0.30-0.42)$.

Three negative symptom scales and five social environment scales were significantly correlated. In particular, moderate to strong correlations were found for the 
Table 2 Distribution of social environment variables $(n=2758)$

\section{Variable}

\section{Ward arrangements (\%)}

Single-gender ward

7 or more patients per ward

Patients served supper before 5 p.m.

Bathroom opened twice or less often each week

Patients allowed to take a bath only in the morning

Patients not allowed to manage pocket money

Possession of three or more daily necessities prohibited

Social environment scale scores (mean (s.d.))

Nurses' opinions about patients (0-9)

Number of personal possessions (0-2I)

Ward restrictiveness $(0-35)$

I. Other scales shown in Table I.

negative symptom scales with nurses' positive opinions about patients and number of personal possessions: coefficients ranged from 0.28 to 0.58 (from 0.30 to 0.54 using the criteria of Wing \& Brown (1970)). The correlations with the Ward Restrictiveness
Scale, which is considered to be an objective variable, relatively independent of the condition of the patients, were between $r=0.13$ and $r=0.16$ (from 0.12 to 0.12 using Wing's criteria), which were significant, but did not suggest a particularly strong relationship. Multiple correlation coefficients with the five social environment scales were between 0.41 and 0.62 , and those with the four scales excluding Nurses' Opinions about Patients were between 0.32 and 0.49 .

In contrast, positive symptom scales showed a less consistent relation with social environment scales: coefficients ranged from $r=0.04$ to $r=0.46, R=0.17$ $0.47 \quad(r=0.06-0.46, \quad R=0.17-0.59$, using Wing's criteria). Particularly, the coefficients of 'coherently expressed delusions' were smaller than those obtained from the negative symptom scales. However, correlations with 'incoherence and irrelevance of speech' and WBRS-SES

Table 3 Correlations between clinical condition scales and social environment scales $(n=2758)$

\begin{tabular}{|c|c|c|c|c|c|c|c|}
\hline & \multicolumn{7}{|c|}{ Primary and secondary disabilities (correlations)' } \\
\hline & $\begin{array}{c}\text { Flattened, } \\
\text { incongruous } \\
\text { affect }\end{array}$ & $\begin{array}{c}\text { Poverty of } \\
\text { speech, mute }\end{array}$ & WBRS-SWS & $\begin{array}{l}\text { Coherently } \\
\text { expressed } \\
\text { delusions }\end{array}$ & $\begin{array}{c}\text { Incoherence } \\
\text { and irrelevance } \\
\text { of speech }\end{array}$ & WBRS-SES & $\begin{array}{l}\text { Attitude to } \\
\text { discharge }\end{array}$ \\
\hline Length of stay (years; range I-56) & 0.14 & 0.14 & 0.12 & $-0.02(n s)$ & 0.10 & 0.03 (ns) & 0.21 \\
\hline \multicolumn{8}{|l|}{ Clinical condition scales } \\
\hline \multicolumn{8}{|c|}{ Negative symptoms ('clinical poverty' syndromes) } \\
\hline \multicolumn{8}{|l|}{ Flattened, incongruous affect } \\
\hline Poverty of speech, mute & 0.63 & & & & & & \\
\hline WBRS-SWS & 0.41 & 0.46 & & & & & \\
\hline \multicolumn{8}{|l|}{ Positive symptoms (florid symptoms) } \\
\hline Hallucinations & 0.21 & 0.14 & 0.15 & & & & \\
\hline Incoherence and irrelevance of speech & 0.58 & 0.56 & 0.35 & 0.42 & & & \\
\hline WBRS-SES & 0.24 & 0.21 & 0.36 & 0.30 & 0.39 & & \\
\hline Negative attitude to discharge & 0.16 & 0.17 & 0.12 & $-0.04(n s)$ & 0.10 & $0.02(\mathrm{~ns})$ & \\
\hline \multicolumn{8}{|l|}{ Social environment scales } \\
\hline \multicolumn{8}{|l|}{ Pearson's correlations } \\
\hline Nurses' opinions about patients & -0.39 & -0.40 & -0.58 & -0.22 & -0.46 & -0.46 & -0.08 \\
\hline Number of personal possessions & -0.28 & -0.31 & -0.42 & $-0.04(\mathrm{~ns})$ & -0.23 & -0.19 & -0.08 \\
\hline Contact with outside world & -0.15 & -0.15 & -0.24 & -0.08 & -0.18 & -0.14 & -0.15 \\
\hline Patient's occupation & -0.21 & -0.19 & -0.32 & -0.17 & -0.21 & -0.20 & -0.09 \\
\hline Ward restrictiveness & 0.14 & 0.13 & 0.16 & 0.04 (ns) & 0.17 & 0.11 & 0.01 (ns) \\
\hline \multicolumn{8}{|l|}{ Multiple correlation coefficients } \\
\hline Five social environment scales & 0.41 & 0.43 & 0.62 & 0.25 & 0.46 & 0.47 & 0.17 \\
\hline $\begin{array}{l}\text { Social environment scales without nurses' } \\
\text { opinions }\end{array}$ & 0.32 & 0.34 & 0.49 & 0.17 & 0.30 & 0.25 & 0.17 \\
\hline
\end{tabular}

SES, Socially Embarrassing Behaviour Score; SWS, Social Withdrawal Score; WBRS, Ward Behaviour Rating Scale.

I. All correlations significant $(P<0.001)$ except those marked $(n s)$. 
were similar to those with negative symptom scales.

The negative attitude to discharge as an index of secondary disabilities was positively correlated with 'flattened, incongruous affect', 'poverty of speech, mute' and WBRS-SWS as indices of negative symptoms. However, no significant correlation was found with positive symptom scales except for 'incoherence and irrelevance of speech'. A weak negative correlation was demonstrated with social environment variables, such as nurses' positive opinions about patients, personal possessions, contact with the outside world, and patient's occupation.

We obtained similar results using the criteria of Wing \& Brown (1970).

\section{DISCUSSION}

\section{Findings}

The findings from our cross-sectional study suggest that long-stay psychiatric patients in Japan have not been significantly influenced by the negative effects of long-term residence in psychiatric hospitals, such as negative attitude to discharge and negative symptoms. However, the environments of hospitals in Japan proved to be severe and a significant degree of ward restrictiveness was identified. We observed that many understimulating social environment variables were significantly correlated with negative symptoms. Although we were not able to establish a causal relationship (owing to the research design) we observed that the multiple correlation coefficients with four social environment scales using negative symptom scales as dependent variables, and the correlations of negative symptoms with the Ward Restrictiveness Scale, were significant.

Among the measures of positive symptoms that we assessed, 'coherently expressed delusions' correlated most weakly with social environment measures. The equivalent correlations demonstrated for WBRS-SES and 'incoherence and irrelevance of speech' were, however, of similar magnitude to those for measures of negative symptoms. One should note, however, that incoherence of thought is reported to correlate highly with negative symptoms (Bilder et al, 1985; Someya, 1990). In terms of the effects of an increase in the length of stay, we found a parallel increase in negative symptoms, and a negative attitude to discharge, whereas positive symptoms,

\section{CLINICAL IMPLICATIONS}

- This study replicated earlier British research that influenced psychiatric hospital reform and promoted the development of community mental health programmes in the UK.

- The Japanese patients showed no apparent negative effects of long-stay hospitalisation compared with patients in the UK.

- The findings suggest the possibility of resettlement of long-stay patients in Japan through appropriate rehabilitation programmes and improvements in the understimulating environments of psychiatric hospitals.

\section{LIMITATIONS}

This was not a random sample of hospitals; those taking part had a positive attitude toward this project, and were likely to have more activities available to patients.

- A cross-sectional design was used to examine the relationship between negative symptoms of schizophrenia and social environments.

- The sample seletion criteria and the assesment scales were not identical to those used in the replicated study.

IWAO OSHIMA, PhD, Department of Mental Health, Tokyo University Graduate School of Medicine, Tokyo; YOSHIO MINO, MD, College of Social Welfare, Osaka Prefecture University, Osaka; YOSHIMASA INOMATA MD, Miyagi Prefecture Natori Hospital, Natori, Japan

Correspondence: Dr Iwao Oshima, Department of Mental Health, Tokyo University Graduate School of Medicine, 7-3-I Hongo, Bunkyo-ku, Tokyo II3-0033, Japan. Tel: 3 584I 3612; fax: 3 584I 3392;

e-mail: i-oshima@aurora.dti.ne.jp

(First received 28 October 2002, final revision 31 January 2003, accepted 19 February 2003)

excluding 'incoherence and irrelevance of speech', showed no such increase. We identified a similar influence of prolonged stay in a psychiatric hospital on the exacerbation of negative symptoms and negative attitude to discharge to that reported by Wing \& Brown (1970). Our findings therefore appear to replicate those of Wing $\&$ Brown.

With regard to severe social environments, many hospitals in Japan do not provide appropriate social roles for psychiatric in-patients. The Patient's Occupation Scale score was noticeably lower than that in the British studies. This raises the concern that although a relatively low proportion of long-stay patients have a negative attitude to discharge and negative symptoms, actual activities promoting the discharge of such in-patients are not encouraged.

\section{Limitations and significance of this study}

This research was conducted as a nationwide survey in Japan. The participating hospitals were those that expressed a positive attitude toward this project, and were thought to be hospitals with many activities available to patients. However, we believe that we obtained a relatively representative sample, because most features of the patients and the hospitals studied are consistent with the national statistics in Japan.

Our intention of replicating the study reported by Wing \& Brown (1970) was difficult to achieve, given that after the significant advances in deinstitutionalisation in Europe and in North America, most people with severe persistent mental illness in those areas receive community care. Therefore, we believe that it is important to have 
conducted the replication study in Japan, where the problems of institutionalisation are still under discussion (Zenkaren Health and Welfare Research Institute, 1998; Oshima et al, 2002). Notably, we obtained almost the same results using a crosssectional design and national samples covering over $12 \%$ of psychiatric beds in Japan. This nationwide survey had several purposes, such as assessing the need for community support resources. Therefore, we were unable to strictly replicate the study of Wing \& Brown (1970); in addition, we did not select the same criteria for samples, nor did we use the exact scales.

\section{Implications}

Psychiatric hospitals in Japan have understimulating social environments, and although the proportions of in-patients with negative symptoms or negative attitudes to discharge are lower than was found in the British studies (Wing \& Brown, 1970; Curson, 1992), it is still vital to address these issues within psychiatric hospitals and to encourage communitybased treatment. Patients who do not have severe symptoms still remain in psychiatric hospitals with poor conditions for extended periods, since there are few alternatives to hospital-based care. These individuals should be provided with systematic treatment in the community, such as assertive community treatment or intensive case management, which have been proved to be effective in evidence-based practice for people with severe, persistent mental illness (Mueser et al, 1998), and with other effective community programmes that have been developed empirically from deinstitutionalisation and community mental health practices in Europe and in the USA (Watts \& Bennett, 1991).

\section{ACKNOWLEDGEMENTS}

The authors thank Dr Trevor Hadley and Dr Eri Kuno for their helpful comments. The nationwide survey was conducted by the research committee: Y. Inomata (Chair), Y. Mino, S. Inoue, A. Yoshizumi, Y. Kawazoe, K. Okagami, I. Oshima, K. Inazawa, Y. Igarashi, Y. Ueki, K. Kon, Y. Saito, Y. Sawa T. Takayama, T. Takizawa, I. Terada and T. Yamada. It was funded and organised by the National Federation of Families with the Mentally III in Japan (Zenkaren). Other funding was supplied by the Bureau for the Elderly, Ministry of Health and Welfare in Japan.

\section{REFERENCES}

American Psychiatric Association (1987) Diagnostic and Statistical Manual of Mental Disorders (3rd edn, revised) (DSM-III-R). Washington, DC: APA.

Bilder, R. M., Mukherjee, S., Rieder, R. O., et al (1985) Symptomatic and neuropsychological components of defect states. Schizophrenia Bulletin, II, 409-419.

Curson, D. A., Pantelis, C., Ward, J., et al (1992) Institutionalism and schizophrenia 30 years on. Clinical poverty and the social environment in three British mental hospitals in 1960 compared with a fourth in 1990 British Journal of Psychiatry, 160, 230-24l.

Krawiecka, M., Goldberg, D. \& Vaughan, M. (1977) A standardized psychiatric assessment scale for rating chronic psychotic patients. Acta Psychiatrica Scandinavica, 55, 299-308.

Lamb, H. R. \& Weinberger, L. E. (eds) (200I) Institutionalization: Promise and Problems. San Francisco, CA: Jossey-Bass.

Leff, J. (ed.) (1993) The TAPS Project: evaluating community placement of long-stay psychiatric patients. British Journal of Psychiatry, 162 (suppl. 19), I-56.

Ministry of Health and Welfare (1999) Patient Survey 1996 [in Japanese]. Tokyo: Statistics and Information Department, MHW.

Mino, Y., Kodera, R. \& Bebbington, P. (1990) A comparative study of psychiatric services in Japan and England. British Journal of Psychiatry, 157, 416-420.

Mueser, K. T., Bond, G. R., Drake, R. E., et al (1998) Models of community care for severe mental illness: a review of research on case management. Schizophrenia Bulletin, 24, 37-74.

Oshima, I., Yoshizumi, A., Inazawa, K., et al (1996) Long-stay inpatients' expressed needs and hopes about community living after discharge from psychiatric hospitals in Japan: an analysis of a nationwide selfrating survey for long stay schizophrenics in about 40000 psychiatric beds in Japan [in Japanese]. Japanese Journal of Hospital and Community Psychiatry, 38, 558-567.

_ , Ito, J. \& Taira, N. (2002) Need for an integrated program of case management and psychoeducation in long stay psychiatric patients in Japan. In Comprehensive Treatment of Schizophrenia: Linking Neurobehavioral Findings to Psychosocial Approaches (eds H. Kashima, I. R. H. Falloon, M. Mizuno, et al), pp. 196-203. Berlin: Springer.

Salokangas, R. K. R. \& Saarinen, S. (1998) Deinstitutionalization and schizophrenia in Finland: I. Discharged patients and their care. Schizophrenia Bulletin, 24, 457-467.

Someya, T. (1990) Independence and validity of negative symptoms [in Japanese]. Japanese Archives of Psychiatric Evaluation, I, 339-347.

Takekawa, Y., Hori, A., Tsunashima, K., et al (1994) Reliability and validity of Japanese version of Manchester Scale [in Japanese]. Seishinigaku, 36, 389-394.

Watts, F. N. \& Bennett, D. H. (199I) Theory and Practice of Psychiatric Rehabilitation. Chichester: John Wiley \& Sons.

Wing, J. K. (1961) A simple and reliable subclassification of chronic schizophrenia. Journal of Mental Science, 107, 862-875.

_ \& Brown, G.W. (1970) Institutionalism and Schizophrenia. London: Cambridge University Press.

Zenkaren Health and Welfare Research Institute (1994) The Needs of Care and Support of People with Mental Disorders and Their Families (III): A Nationwide Survey of Long-stay Psychiatric Patients in Japan [in Japanese]. Zenkaren Health and Welfare Institute Monograph 7. Tokyo: Zenkaren.

- (1998) Research on Institutional Care for Long-term Inpatients in Japan [in Japanese]. Zenkaren Health and Welfare Institute Monograph 15. Tokyo: Zenkaren.

- (2000) Current Status of People with Severe Mental IIInesses in Japan: an Analysis of Nationwide Statistics [in Japanese]. Zenkaren Health and Welfare Institute Monograph 26. Tokyo: Zenkaren. 